\title{
Microstructure and Mechanical Property Improvement of Laser Additive Manufacturing Ti-6Al-4V via the Niobium Addition
}

\author{
Chenyang Wang, Chun Shang*, Guojian Xu*, Zhicheng Jing, Jin Liu and Yunhai Su \\ School of Material Science and Engineering, Shenyang University of Technology, Shenyang 110870, China
}

Titanium alloys with high specific strength have widespread applications within the aerospace industry. However, the direct fabrication of titanium alloys with excellent performance is very difficult using traditional manufacturing techniques. In the present work, we adopted advanced laser additive manufacturing (LAM) technology to fabricate Ti-6Al-4V titanium alloy via the addition of Niobium (Nb), which result in the improvement of mechanical properties. The effects of $\mathrm{Nb}$ additions on microstructure, phase composition, and mechanical properties of $\mathrm{Ti}-6 \mathrm{Al}-4 \mathrm{~V}$ alloys were investigated. Research results showed that the addition of $\mathrm{Nb}$ not only significantly refined the original $\beta$-Ti and the primary acicular $\alpha$-Ti structure, but also increased the content of $\beta$-Ti to some extent, which contributed to improving both the strength and plasticity of the material. The tensile strength, yield strength, the elongation, and the section shrinkage of the Ti-6Al-4V+Nb increased by $15.2 \%, 6.9 \%, 2.6 \%$, and $7.4 \%$, respectively, compared with Ti-6Al-4V, which exceeded the required forging standard.

[doi:10.2320/matertrans.MT-M2019370]

(Received December 16, 2019; Accepted January 17, 2020; Published February 21, 2020)

Keywords: laser additive manufacturing (LAM), Ti-6Al-4V, microstructure, properties

\section{Introduction}

Titanium alloys have wide applications in the aerospace field ${ }^{1,2)}$ due to their excellent properties such as low density $\left(4.5 \mathrm{~g} / \mathrm{cm}^{3}\right)$, high strength to density ratio, good corrosion resistance and thermal stability. At present, structural parts used in the aerospace industry are mostly manufactured by the forging process. ${ }^{3)}$ However, this traditional process is not sufficient to meet the requirements of high mechanical properties and complex structures in manufacturing titanium alloys. In recent years, laser additive manufacturing (LAM) technology has received extensive attention as it provides a new approach for fabricating complex structures in the aerospace field. ${ }^{4-6)}$ However, the properties of titanium alloys fabricated by LAM usually cannot usually reach the required forging standard, and heat treatment processes are usually required to achieve this standard. ${ }^{7-9)}$ For example, some previous studies adopted the subsequent heat treatment process for changing the morphology and relative content of $\alpha-\mathrm{Ti}$ and $\beta$ - Ti in $\mathrm{Ti}-6 \mathrm{Al}-4 \mathrm{~V}$, which contributed to an improvement in the mechanical properties. ${ }^{10,11)}$ But subsequent heat treatment brings many problems such as high manufacturing costs and long production cycles, which limit the development of LAM titanium alloys to some extent.

In order to solve the above problems caused by the subsequent heat treatment, some scientists have adopted alloying technology to improve the microstructure and mechanical properties of $\mathrm{Ti}-6 \mathrm{Al}-4 \mathrm{~V}$ alloy by the addition of alloying elements during LAM. ${ }^{12)}$ Teddy et al. ${ }^{13)}$ investigated the effect of Fe additions on the microstructure and properties of as-cast titanium alloys and found that the strength was increased with an increase of Fe. Wang et al. ${ }^{14)}$ studied the influence of $\mathrm{Nb}$ content on the microstructure of $\mathrm{Ti}-\mathrm{Nb}$ alloys fabricated via selective laser melting and found that $\mathrm{Nb}$ could decrease the dimension of the original $\beta$ grains and increase the amount of $\beta$-Ti, which result in the

*Corresponding authors, E-mail: gjxu1959@163.com, cshangsau@163. com improvement of mechanical properties. Fu et al. ${ }^{15)}$ investigated the effect of the addition of $\mathrm{Nb}$ on the microstructure and properties of as-cast titanium alloys, and the research indicated that due to the addition of $\mathrm{Nb}$, the compressive strength and yield strength of as-cast titanium alloys were improved to some extent. Adam et al. ${ }^{16)}$ studied the effect of the $\mathrm{Nb}$ element on the selective laser melting of TiAl alloy and showed that the addition of $\mathrm{Nb}$ was able to improve the strength and toughness of the TiAl alloy. Based on the above research results, $\mathrm{Nb}$ should be an ideal element to improve the properties of titanium alloys.

In this paper, Ti-6Al-4V titanium alloy which has widespread prospects for applications as important components in the aerospace industry, was chosen as a suitable candidate for investigating the effect of $\mathrm{Nb}$ addition on the titanium alloy. The specimens of Ti-6Al-4V and Ti-6Al$4 \mathrm{~V}+\mathrm{Nb}$ were fabricated by LAM. The effect of the $\mathrm{Nb}$ addition on the microstructure and properties of Ti-6Al-4V alloy were investigated. We found that the addition of $\mathrm{Nb}$ could refine the microstructure and improve the mechanical properties, which exceeded the required forging standard.

\section{Materials and Experimental Procedures}

The base material used in the experiment was a hot-rolled Ti-6Al-4V alloy sheet, whose size was $100 \mathrm{~mm} \times 50 \mathrm{~mm} \times$ $20 \mathrm{~mm}$. The substrate surfaces were polished by sandpaper and then cleaned in alcohol or acetone before the LAM. Figure 1 shows that two square block samples were deposited by LAM. The powder materials used for the LAM process were $\mathrm{Ti}-6 \mathrm{Al}-4 \mathrm{~V}$ and $\mathrm{Nb}$ (purity 99.99\%) powders, purchased from Falcontech CO. LTD (Wuxi, Jiangsu, China). The Ti-6Al-4V powder was in a particle size range of $150 \mu \mathrm{m} / 300 \mu \mathrm{m}$, while the $\mathrm{Nb}$ powder was in a particle size range of $100 \mu \mathrm{m} / 200 \mu \mathrm{m}$. The chemical composition of the Ti-6Al-4V powder is shown in Table 1. The two powders were mixed in the weight ratio Ti-6Al$4 \mathrm{~V}: \mathrm{Nb}=23: 2$, by ball milling for three hours. For achieving a better melting of the $\mathrm{Nb}$ and a full metallurgical reaction 
(a)

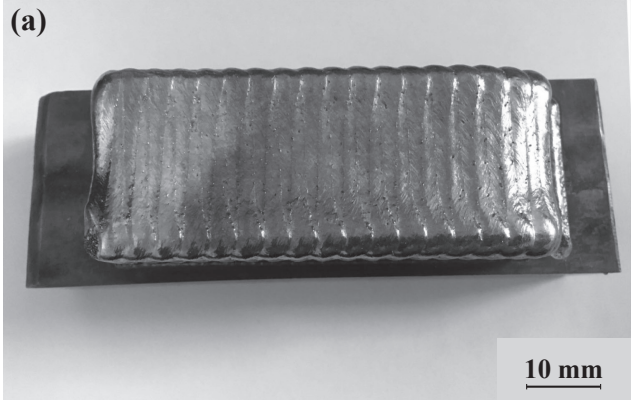

(b)

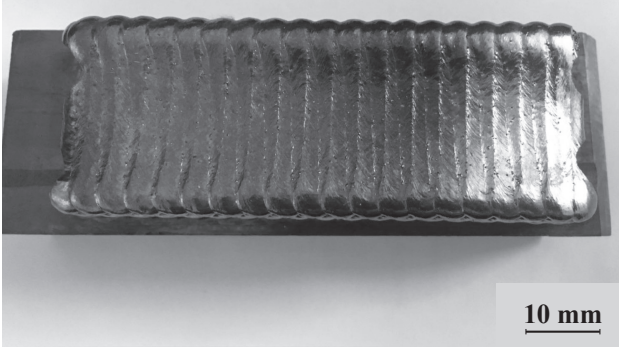

Fig. 1 Photograph of the as-deposited state specimen (a) Ti-6Al-4V, (b) $\mathrm{Ti}-6 \mathrm{Al}-4 \mathrm{~V}+\mathrm{Nb}$.

Table 1 Chemical composition of Ti-6Al-4V alloy powder.

\begin{tabular}{ccccccccc}
\hline Element & Ti & Al & V & Fe & C & H & O & N \\
\hline Mass & Balance & $5.5 \sim 6.8$ & $3.5 \sim 4.5$ & $\leqq 0.30$ & $\leqq 0.10$ & $\leqq 0.015$ & $\leqq 0.20$ & $\leqq 0.05$ \\
fraction/\% & & & & & & & & \\
\hline
\end{tabular}

Table 2 LAM processing parameters.

\begin{tabular}{ccccccc}
\hline & Laser & Laser scan & & Beam & Layer \\
Powder & power & Powder feeding & Scanning & diameter & thickness \\
& $(\mathrm{kW})$ & rate $(\mathrm{g} / \mathrm{min})$ & $\begin{array}{c}\text { pitch } \\
(\mathrm{mm} / \mathrm{s})\end{array}$ & $(\mathrm{mm})$ & $(\mathrm{mm})$ \\
\hline Ti-6Al-4V+Nb & 2300 & 0.8 & 8.0 & 2.0 & 3.0 & 0.6 \\
Ti-6Al-4V & 2000 & 1.0 & 8.0 & 2.0 & 3.0 & 0.6 \\
\hline
\end{tabular}

with $\mathrm{Ti}-6 \mathrm{Al}-4 \mathrm{~V}, \mathrm{Nb}$ powder with a smaller particle size than the $\mathrm{Ti}-6 \mathrm{Al}-4 \mathrm{~V}$ powder was selected, because the melting point of $\mathrm{Nb}\left(2477^{\circ} \mathrm{C}\right)$ is much higher than that of Ti-6Al-4V $\left(1678^{\circ} \mathrm{C}\right)$. In order to prevent the titanium alloy powder from being contaminated, the factory adopts a vacuum package as the vessel. Before the LAM experiment, the powder was heated at $100^{\circ} \mathrm{C}$ for 1 hour to remove the moisture in a vacuum furnace or an inert gas (Ar) furnace. Besides, the replacement of the powder was in an inert gas (Ar) environment. Therefore, none of the powder used in the experiment was contaminated.

The LAM equipment system was independently developed and produced by Raycham CO. LTD (Nanjing, Jiangsu, China) with a coaxial powder feeding laser solid forming system equipped with a $6000 \mathrm{~W}$ fibre laser. To prevent the samples from oxidizing, the whole experiment process was performed under an argon atmosphere chamber, and ensured the oxygen level to be lower than $20 \mathrm{ppm}$. Based on preliminary experiments, the adopted optimised LAM processing parameters are shown in Table 2.

Metallographic samples and room temperature tensile samples were prepared along the direction perpendicular to the laser scanning. The as-deposited metallographic samples were first polished, and then chemically etched by the reagent (HF:HNO3:H2O = 2:3:10 for Ti-6Al-4V; HF: $\mathrm{HNO}_{3}: \mathrm{H}_{2} \mathrm{O}=$ $1: 6: 7$, for $\mathrm{Ti}-6 \mathrm{Al}-4 \mathrm{~V}+\mathrm{Nb}$ ) for $1 \mathrm{~min}$. The microstructural characterisation of the two samples was performed by scanning electron microscope (SEM, SU8010). The elemental distribution across the interfaces was investigated by the energy dispersive x-ray spectroscopy (EDS). In order to analyse the situation of the phases on the fracture surface, $\mathrm{X}$-ray diffraction (XRD) tests were investigated using an XRD7000-type diffractometer at a scanning speed of $4^{\circ} / \mathrm{min}$ from $20^{\circ} \sim 90^{\circ}$. The tensile properties of the bimetallic structure were tested on a WDW-3100 tensile testing machine with an extensometer, at an invariable tensile rate of 1.0 $\mathrm{mm} / \mathrm{min}$. The grain size and the area ratio were measured using the Digital Micrograph 3.7 software.

\section{Results and Discussion}

\subsection{Microstructure}

The cross-section OM images of Ti-6Al-4V and Ti-6Al$4 \mathrm{~V}+\mathrm{Nb}$ are shown in Fig. 2. Clearly, compared with the Ti$6 \mathrm{Al}-4 \mathrm{~V}$ deposition state, it can be seen that the original $\beta$-Ti grains of the $\mathrm{Ti}-6 \mathrm{Al}-4 \mathrm{~V}+\mathrm{Nb}$ are remarkably refined (the yellow dotted line is the grain boundary of the original $\beta$-Ti grain). The microstructure of Ti-6Al-4V sample consists of coarse columnar crystals with an average grain size of $1397.5 \mu \mathrm{m} \times 517.56 \mu \mathrm{m}$. The microstructure of Ti-6Al-4V+ $\mathrm{Nb}$ consists of a large number of equiaxed grains with an average grain size of $629.7 \mu \mathrm{m} \times 314.1 \mu \mathrm{m}$. This shows that 

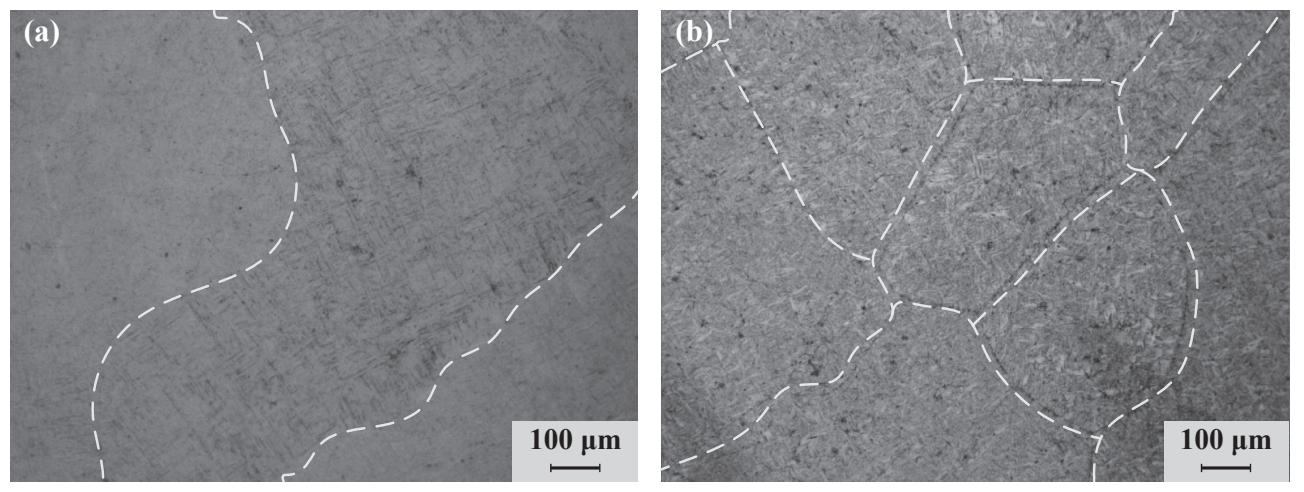

Fig. 2 LAM deposition state sample $\mathrm{OM}$ (a) as-deposited Ti-6Al-4V, (b) as-deposited Ti-6Al-4V+Nb.
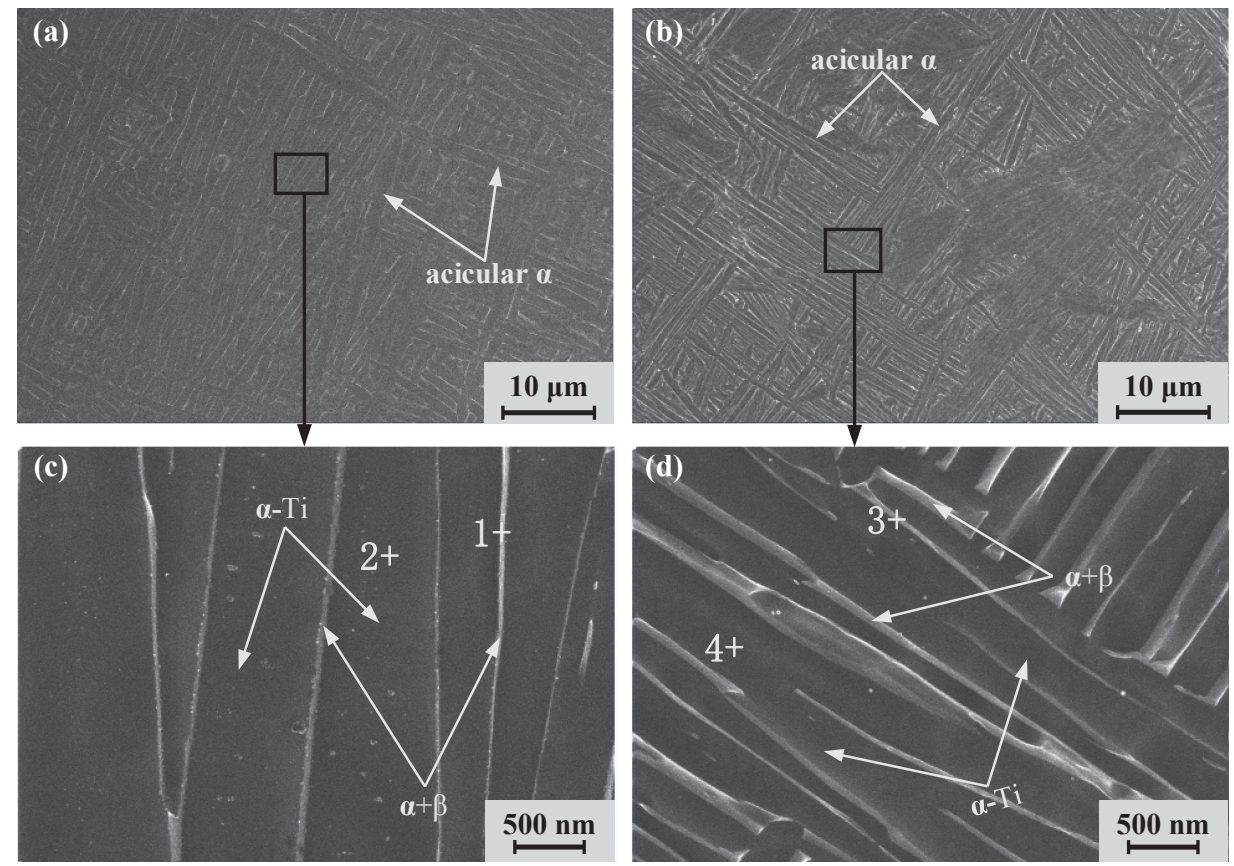

Fig. 3 LAM as-deposited state SEM image (a) Ti-6Al-4V as-deposited state, (b) Ti-6Al-4V+Nb as-deposited state, (c) rectangular frame position enlarged photo in Fig. 3(a), (d) rectangular frame position enlarged photo in Fig. 3(b).

the addition of $\mathrm{Nb}$ can refine the original $\beta$-Ti grains in the Ti-6Al-4V. Furthermore, the constitutional fluctuations of $\mathrm{Nb}$ lead to spontaneous nucleation in the molten pool during the solidification, due to $\mathrm{Nb}$ having a higher melting point $\left(2477^{\circ} \mathrm{C}\right)$. So, it can be inferred that the number of nucleations in the $\mathrm{Ti}-6 \mathrm{Al}-4 \mathrm{~V}+\mathrm{Nb}$ sample is much higher than that in Ti-6Al-4V sample during cooling. Secondly, the addition of $\mathrm{Nb}$ could increase the concentration of solute and constitutional supercooling of the molten pool, which contributes to promoting the spontaneous nucleation rate and refining the microstructure.

SEM images of $\mathrm{Ti}-6 \mathrm{Al}-4 \mathrm{~V}$ and $\mathrm{Ti}-6 \mathrm{Al}-4 \mathrm{~V}+\mathrm{Nb}$ are shown in Fig. 3. Figure 3(a) shows that the microstructure of $\mathrm{Ti}-6 \mathrm{Al}-4 \mathrm{~V}$ consists of primary acicular $\alpha$-Ti and a basketweave structure. The primary acicular $\alpha$-Ti precipitates from the original $\beta$-Ti grains with an average size of about $15.2 \mu \mathrm{m} \times 1.4 \mu \mathrm{m}$. The basketweave structure consists of short $\operatorname{rod} \alpha-\mathrm{Ti}$ and $\alpha-\mathrm{Ti}+\beta$-Ti (grain boundary structure, which is distributed between the short $\left.\operatorname{rod} \alpha-\mathrm{Ti}^{7}, 17\right)$ and the basketweave structure also precipitated from the original $\beta$-Ti grains, which have an area ratio of about $73.56 \%$. The widths of the short rod $\alpha$-Ti, and $\alpha$-Ti+ $\beta$-Ti (grain boundary structure) are about $812.93 \mathrm{~nm}$ and $44.83 \mathrm{~nm}$, respectively, and the area ratio of $\alpha-\mathrm{Ti}+\beta$-Ti is about $4.7 \%$.

An enlarged image of the microstructure in $\mathrm{Ti}-6 \mathrm{Al}-4 \mathrm{~V}$ is presented in Fig. 3(c). In order to determine the elemental distribution of the extremely fine $\alpha+\beta$ grain boundary, and the grey-black area $(\alpha$-Ti), the EDS component analysis was carried out, the results of which are shown in Table 3. According to the analysis results of EDS, it can be seen that the $\mathrm{V}$ content in the $\alpha+\beta$ grain boundary is significantly higher than that in the grey-black region, with about 2.8 times the $\mathrm{V}$ content in the grey-black regions. $\mathrm{V}$ (atomic radius about $135 \mathrm{pm}$ ) is a stable element of $\beta$-Ti, which dissolves in $\beta$-Ti to displace the Ti atoms (atomic radius about $145 \mathrm{pm}$ ) and form a substitutional solid solution. According to the report, ${ }^{18)}$ the bright white structure in the as-deposited state Ti-6Al-4V consists of $\alpha$-Ti and $\beta$-Ti. Due to the existence of $\beta$-Ti, the content of the $\beta$-Ti stable element (V) in this region is higher than that in the $\alpha$-Ti region. In addition, LAM is a non-equilibrium solidification process because of the features of rapid heating and rapid cooling. Therefore, in the $\alpha+\beta$ 
Table 3 EDS component analysis results of Ti-6 Al- $4 \mathrm{~V}$ and $\mathrm{Ti}-6 \mathrm{Al}-4 \mathrm{~V}+\mathrm{Nb}$ as-deposited state.

\begin{tabular}{ccccc}
\hline $\begin{array}{c}\text { Position/ } \\
\text { element content }\end{array}$ & $\mathrm{Ti} / \mathrm{wt} \%$ & $\mathrm{Al} / \mathrm{wt} \%$ & $\mathrm{Nb} / \mathrm{wt} \%$ & $\mathrm{~V} / \mathrm{wt} \%$ \\
\hline 1 & 84.93 & 8.04 & - & 7.03 \\
2 & 89.73 & 7.80 & - & 2.47 \\
3 & 83.32 & 6.11 & 5.97 & 4.60 \\
4 & 88.21 & 7.08 & 3.08 & 1.63 \\
\hline
\end{tabular}

two-phase region, $\beta$-Ti has a shorter time to transform to $\alpha$-Ti, resulting in an incomplete $\beta$-Ti phase transition. Accordingly, a certain amount of residual $\beta$-Ti would be present in as-deposited-state structure at room temperature.

Figure 3(b) presents the SEM image of the Ti-6Al-4V+ $\mathrm{Nb}$ sample, which also consists of primary acicular $\alpha$-Ti and the basketweave structure. However, compared with the Ti$6 \mathrm{Al}-4 \mathrm{~V}$ in the as-deposited-state, the size of the primary acicular $\alpha$-Ti $(10.48 \mu \mathrm{m} \times 0.65 \mu \mathrm{m})$ and the short $\operatorname{rod} \alpha$-Ti width $(274.54 \mathrm{~nm})$ are significantly reduced, by about 2.1 times and 2.9 times, respectively. Meanwhile, the area ratio of the basketweave structure is about $91.33 \%$, an increase of about 1.2 times as compared with $\mathrm{Ti}-6 \mathrm{Al}-4 \mathrm{~V}$, which could improve the mechanical properties. The width of $\alpha+\beta$ grain boundary structure in $\mathrm{Ti}-6 \mathrm{Al}-4 \mathrm{~V}+\mathrm{Nb}$ is about $105.82 \mathrm{~nm}$ and the area ratio of $\alpha+\beta$ grain boundary structure is about $24.2 \%$. In comparison with $\mathrm{Ti}-6 \mathrm{Al}-4 \mathrm{~V}$, the area ratio and the width of $\alpha+\beta$ grain boundary structure increased by 5.1 times, and 2.3 times, respectively, indirectly illustrating that the content of $\beta$-Ti is increased. In addition, the orientation of the adjacent basketweave structure is approximately perpendicular to each other.

Figure 3(d) shows the further enlarged image of the microstructure in $\mathrm{Ti}-6 \mathrm{Al}-4 \mathrm{~V}+\mathrm{Nb}$. The EDS component analysis was performed on the area of the short $\operatorname{rod} \alpha$-Ti (grey black) and $\alpha+\beta$ (white bright), the results of which are shown in Table 3. The results show that the $\mathrm{Nb}$ and $\mathrm{V}$ contents in the $\alpha+\beta$ region are higher than those in short rod-shaped regions, an increase of 2 times and 2.8 times, respectively. Both of $\mathrm{Nb}$ (atomic radius about $142.9 \mathrm{pm}$ ) and $\mathrm{V}$ are stable elements of $\beta$-Ti, and their atomic radii are similar to that of the $\mathrm{Ti}$ atom. Therefore, $\mathrm{Nb}$ and $\mathrm{V}$ are easy to dissolve in $\beta$ - Ti to form a substitutional solid solution. ${ }^{19,20)}$ The results of EDS also indirectly indicate that $\beta$-Ti exists at the $\alpha+\beta$ grain boundary of the basketweave structure. In addition, $\mathrm{Nb}$ could reduce the temperature of the $\beta$-Ti phase transition and result in limiting the growth of $\alpha$-Ti. More residual $\beta$-Ti would be obtained at room temperature because with the $\mathrm{Nb}$ lattice type being the same as $\beta$-Ti (bcc), it can be infinitely dissolved in Ti over a large range, so stabilising part of the $\beta$ Ti from the high temperature to room temperature. ${ }^{21,22)}$

\subsection{Phase composition}

The X-ray diffraction patterns of the Ti-6Al-4V and Ti$6 \mathrm{Al}-4 \mathrm{~V}+\mathrm{Nb}$ are shown in Fig. 4. It can be seen that the $\mathrm{X}$-ray diffraction patterns of $\mathrm{Ti}-6 \mathrm{Al}-4 \mathrm{~V}$ and $\mathrm{Ti}-6 \mathrm{Al}-4 \mathrm{~V}+\mathrm{Nb}$ show $\alpha$-Ti and $\beta$-Ti. This indicates that $\mathrm{Nb}$ is completely

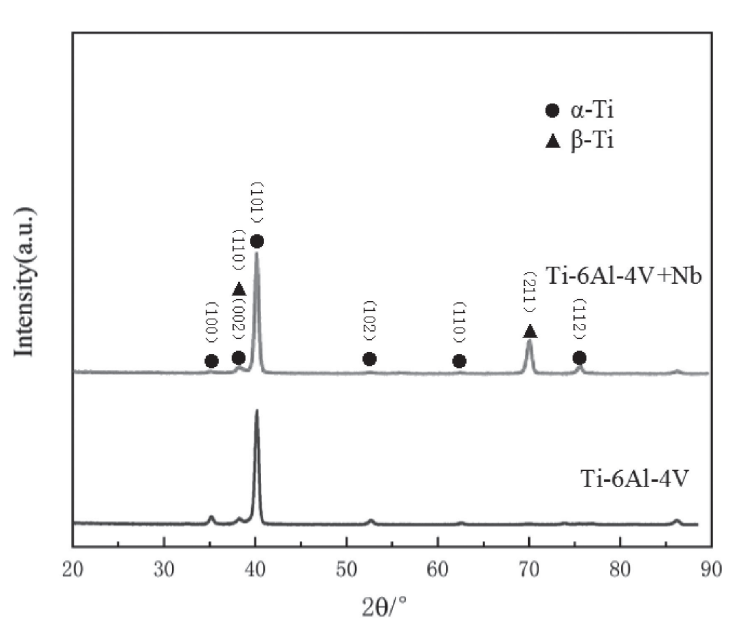

Fig. 4 X-ray diffraction results of $\mathrm{Ti}-6 \mathrm{Al}-4 \mathrm{~V}$ and $\mathrm{Ti}-6 \mathrm{Al}-4 \mathrm{~V}+\mathrm{Nb}$ asdeposited state samples.

dissolved in Ti-6Al-4V. A strong $\alpha$-Ti diffraction peak, and a trace $\beta$-Ti diffraction peak are shown in the Ti-6Al-4V. The $\mathrm{Ti}-6 \mathrm{Al}-4 \mathrm{~V}+\mathrm{Nb}$ shows a large number of $\alpha$-Ti diffraction peaks and a small amount of (211) $\beta$-Ti diffraction peaks. From the X-ray diffraction results, it can be inferred that the $\beta$-Ti phase content in $\mathrm{Ti}-6 \mathrm{Al}-4 \mathrm{~V}+\mathrm{Nb}$ is higher than that in Ti-6Al-4V.

\subsection{Mechanical properties}

The room temperature tensile tests were performed on the two samples fabricated by LAM. The XY-direction tensile stress-strain curves of the samples are shown in Fig. 5. The tensile strength $\left(\sigma_{\mathrm{b}}\right)$ of the Ti-6 $\mathrm{Al}-4 \mathrm{~V}$ specimen is about 928.6 $\mathrm{MPa}$, the yield strength $\left(\sigma_{\mathrm{s}}\right)$ is about $841.2 \mathrm{MPa}$, the elongation $(\delta)$ is about $9.7 \%$, and the reduction of area $(\Psi)$ is about $22.4 \%$. The mechanical properties of $\mathrm{Ti}-6 \mathrm{Al}-4 \mathrm{~V}+\mathrm{Nb}$ specimen are $\sigma_{\mathrm{b}} \approx 1069.7 \mathrm{MPa}, \sigma_{\mathrm{s}} \approx 890.72 \mathrm{MPa}, \delta \approx 12.3 \%$ and $\Psi \approx 29.8 \%$. Clearly, the $\mathrm{Ti}-6 \mathrm{Al}-4 \mathrm{~V}+\mathrm{Nb}$ shows relatively better strength and plasticity and it has exceeded the standard required for $\mathrm{Ti}-6 \mathrm{Al}-4 \mathrm{~V}$ alloy forgings $\left(\sigma_{\mathrm{b}}=\right.$ $895 \mathrm{MPa}, \sigma_{\mathrm{s}}=828 \mathrm{MPa}, \delta=10 \%, \Psi=25 \%$ ).

The increase of $\sigma_{\mathrm{b}}$ and $\sigma_{\mathrm{s}}$ in $\mathrm{Ti}-6 \mathrm{Al}-4 \mathrm{~V}+\mathrm{Nb}$ is due to the addition of $\mathrm{Nb}$ resulting in solution strengthening. Meanwhile, the addition of $\mathrm{Nb}$ also significantly refines the microstructure, which produces fine crystal reinforcing and grain boundary strengthening. The yield strength $\left(\sigma_{\mathrm{s}}\right)$ can be calculated as follows: 


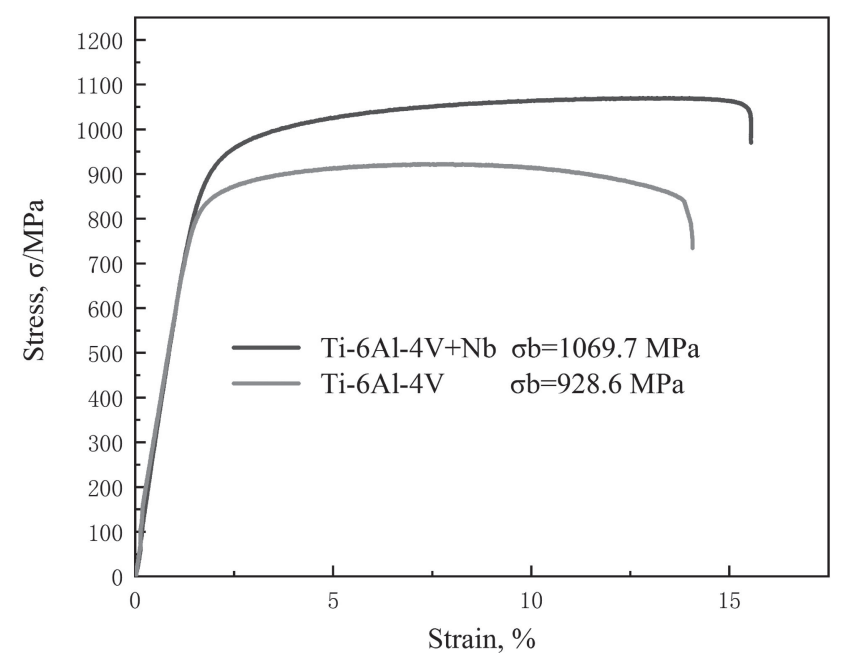

Fig. 5 Room temperature tensile stress-strain curves of the Ti-6Al-4V and $\mathrm{Ti}-6 \mathrm{Al}-4 \mathrm{~V}+\mathrm{Nb}$ as-deposited state samples.

$$
\sigma_{s}=\sigma_{0}+K d^{-\frac{1}{2}}
$$

Where $\sigma_{\mathrm{s}}$ is the polycrystalline yield strength, $\mathrm{d}$ is the average grain diameter, $\sigma_{0}$ is the resistance of dislocations within the grain, and $\mathrm{K}$ is related to the grain boundary structure.

According to formula (1), the finer the grain diameter, the higher the yield strength. The addition of $\mathrm{Nb}$ results in the increase of $\delta$ and $\Psi$, which could generate more $\beta$-Ti at room temperature. The lattice type of $\beta$-Ti is body-centred cubic, which has more slip coefficients than the close-packed hexagonal lattice $\alpha$-Ti. ${ }^{23}$ Compared with the Ti-6Al-4V, the finer primary acicular $\alpha$-Ti and the basketweave structure are formed in $\mathrm{Ti}-6 \mathrm{Al}-4 \mathrm{~V}+\mathrm{Nb}$, and the angle between the adjacent basketweaves is about $90^{\circ}$. When a crack tip is $90^{\circ}$ to the short rod $\alpha$-Ti in the basket structure, it could be passivated and cause a hindrance to crack propagation, which would reduce the crack sensitivity. ${ }^{24,25)}$ Based on the above reasons, the plasticity of $\mathrm{Ti}-6 \mathrm{Al}-4 \mathrm{~V}+\mathrm{Nb}$ is improved.

The fracture surfaces of the tensile specimens of Ti-6Al$4 \mathrm{~V}$ and $\mathrm{Ti}-6 \mathrm{Al}-4 \mathrm{~V}+\mathrm{Nb}$ are shown in Fig. 6. A large number of dimples can be seen in both specimens indicating that both are plastic fractures. However, comparing the morphology of the two specimens, the $\mathrm{Ti}-6 \mathrm{Al}-4 \mathrm{~V}+\mathrm{Nb}$ specimen has the deeper dimples, indicating it has better plasticity.

\section{Conclusions}

The Ti-6Al-4V and Ti-6Al-4V+Nb samples were fabricated by LAM. The microstructure and mechanical properties of the two samples were compared and analysed. The main conclusions can be summarised as follows:

The addition of $\mathrm{Nb}$ significantly refined the microstructure of Ti-6Al-4V, which led to a reduction in the size of original $\beta$-Ti grains, the width of the acicular $\alpha$-Ti, and the short rod $\alpha$-Ti, of about 2.5 times, 2.1 times, and 2.9 times, respectively. Meanwhile, the addition of $\mathrm{Nb}$ also increased the $\beta$-Ti content and the ratio of $\alpha+\beta$ grain boundary area of $\mathrm{Ti}-6 \mathrm{Al}-4 \mathrm{~V}$ in the deposited state.

The mechanical properties of $\mathrm{Ti}-6 \mathrm{Al}-4 \mathrm{~V}+\mathrm{Nb}$ in the deposited state are: $\sigma_{\mathrm{b}} \approx 1069.7 \mathrm{MPa}, \sigma_{\mathrm{s}} \approx 890.72 \mathrm{MPa}, \delta \approx$ $12.3 \%$, and $\Psi \approx 29.8 \%$. Compared with $\mathrm{Ti}-6 \mathrm{Al}-4 \mathrm{~V}$, this shows an increase of $15.2 \%, 6.9 \%, 2.6 \%$, and $7.4 \%$, respectively, and exceeds the required forging standard $\left(\sigma_{\mathrm{b}}=895 \mathrm{MPa}, \sigma_{\mathrm{s}}=828 \mathrm{MPa}, \delta=10 \%\right.$ and $\left.\Psi=25 \%\right)$.

\section{Acknowledgements}

The work was supported by the National Key Research and Development Program of China under Grant No. 2017YFB1103600.

\section{REFERENCES}

1) C. Shang, G.J. Xu, C.Y. Wang, G. Yang and J.H. You: Mater. Lett. 252 (2019) 342-344.

2) X.Z. Yue, H. Fukazawa, K. Maruyama, K. Matsuo and K. Kitazono: Mater. Trans. 60 (2019) 74-79.

3) X. Yang, Z. Zhao, Y. Ning, H.Z. Guo, H. Li, S.H. Yuan and S.W. Xin: Mater. Sci. Eng. A 745 (2019) 240-251.

4) A. Azarniya, X.G. Colera, M.J. Mirzaali, S. Sovizi, F. Bartolomeu, M.S. Weglowski, W.W. Wits, C.Y. Yap, J. Ahn, G. Miranda, F.S. Silva, H.R.M. Hosseini, S. Ramakrishna and A.A. Zadpoor: J. Alloy. Compd. 804 (2019) 163-191.

5) L.Y. Qin, J.H. Men, L.S. Zhang, S. Zhang, C.F. Li, G. Yang and W. Wang: Mater. Sci. Eng. A 759 (2019) 404-414.

6) K. Akino and K. Kakehi: Mater. Trans. 59 (2018) 482-487.

7) P. Guo, Y.Q. Zhao, W.D. Zeng and Q. Hong: Mater. Sci. Eng. A 563 (2013) 106-111.

8) Z.C. Sun, H.L. Wu, X.Y. Ma, X.J. Mao and H. Yang: J. Mater. Eng. Perform. 25 (2016) 4549-4560.

9) Z.Q. Liu, G.J. Xu, W. Wang, L.L. Chang and X.J. Qiu: J. Shenyang Univ. Technol. 42 (2020) 1-6 (in Chinese).
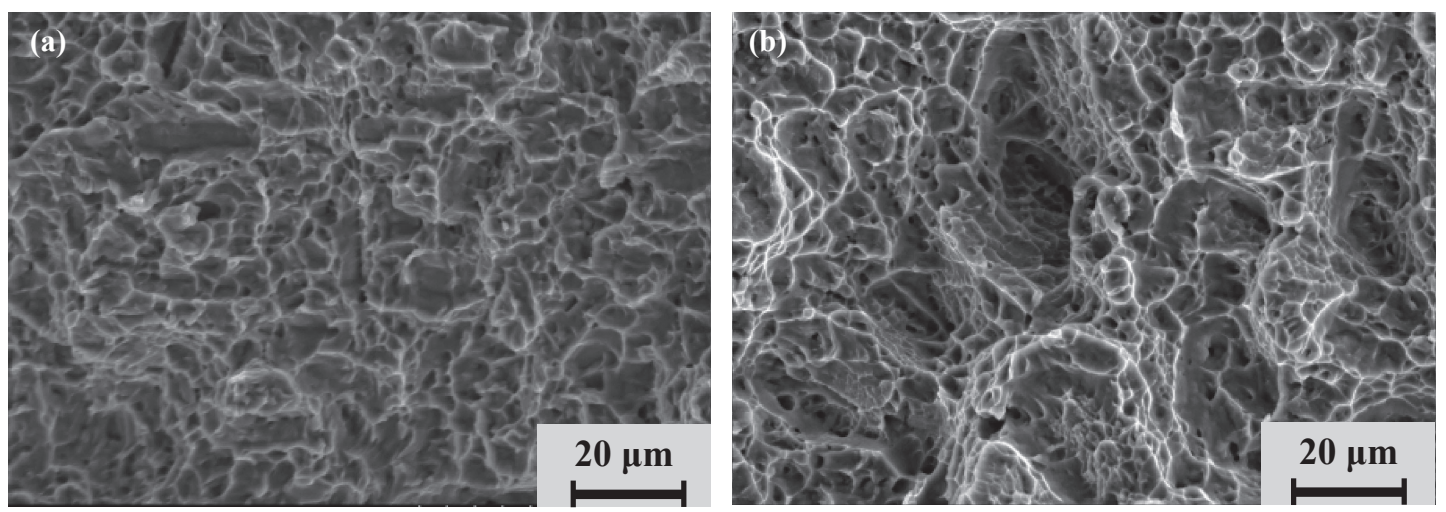

Fig. 6 Fracture surface of room temperature tensile specimens (a) Ti-6Al-4V as-deposited sample, (b) Ti-6Al-4V+Nb as-deposited sample. 
10) S. Ling, S.J. Wu, W.Y. Peng, A. Datye, J.B. Liu, M.A. Lefoul, H. Ju and Y. Liu: Mater. Res. Express. 6 (2019) 056523.

11) G.J. Xu, G.Y. Zhang, W.H. Li, Z.X. Hang and X.J. Qiu: J. Shenyang Univ. Technol. 41 (2019) 154-158 (in Chinese).

12) P.L. Narayana, S.W. Lee, S.W. Choi, C.L. Li, C.H. Park, J.T. Yeom, N.S. Reddy and J.K. Hong: J. Alloy. Compd. 811 (2019) 152021

13) T. Sjafrizal, A.D. Manshadi, D. Kent, M. Yan and M.S. Dargusch J. Mech. Behav. Biomed. 102 (2019) 103518.

14) Q. Wang, C.J. Han, T. Choma, Q.S. Wei, C.Z. Yan, B. Song and Y.S Shi: Mater. Des. 126 (2017) 268-277.

15) B. Fu, H.W. Wang, C.M. Zou and Z.J. Wei: Mater. Des. 66 (2015) $267-$ 273.

16) A. Ismaeel and C.S. Wang: Trans. Nonferrous Met. Soc. China 29 (2019) 1007-1016.

17) M. Muhammad, J.W. Pegues, N. Shamsaei and M. Haghshenas: Int. J. Adv. Manuf. Technol. 103 (2019) 4161-4172.

18) W.G. Zhu, J. Lei, C.S. Tan, Q.Y. Sun, W. Chen, L. Xiao and J. Sun:
Mater. Des. 168 (2019) 107640.

19) P. Neacsu, D.M. Gordin, V. Mitran and T. Gloriant: Mater. Sci. Eng. C 47 (2015) 105-113.

20) S. Bahl, A.S. Krishnamurthy, S. Suwas and K. Chatterjee: Mater. Des. 126 (2017) 226-237.

21) K. Chou and E.A. Marquis: Acta Mater. 181 (2019) 367-376.

22) P. Wang, M. Todai and T. Nakano: J. Alloy. Compd. 766 (2018) 511516.

23) C.D. Rabadia, Y.J. Liu, G.H. Cao, Y.H. Li, C.W. Zhang, T.B. Sercombe, H. Sun and L.C. Zhang: Mater. Sci. Eng. A 732 (2018) 368-377.

24) H. Deng, L.Q. Chen, W.B. Qin, Z. Zheng, Y. Tang, Z.D. Hu, Y.Q. Wei, Z.X. Xia, G.M. Le, J. Tang and X.D. Cui: J. Alloy. Compd. 810 (2019) 151792.

25) A. Reck, S. Pilz, M. Kuczyk, A. Gebert and M. Zimmermann: Mater Sci. Eng. A 761 (2019) 137966. 